\title{
Massive Steinstrasse After Treatment of a Staghorn Calculus
}

\author{
Jennifer Pugliese* and Andrew Peterson \\ Madigan Army Medical Center, Fort Lewis, Tacoma, WA 98431
}

The opinions or assertions contained herein are the private views of the author(s) and are not to be construed as official or as reflecting the views of the Department of Defense
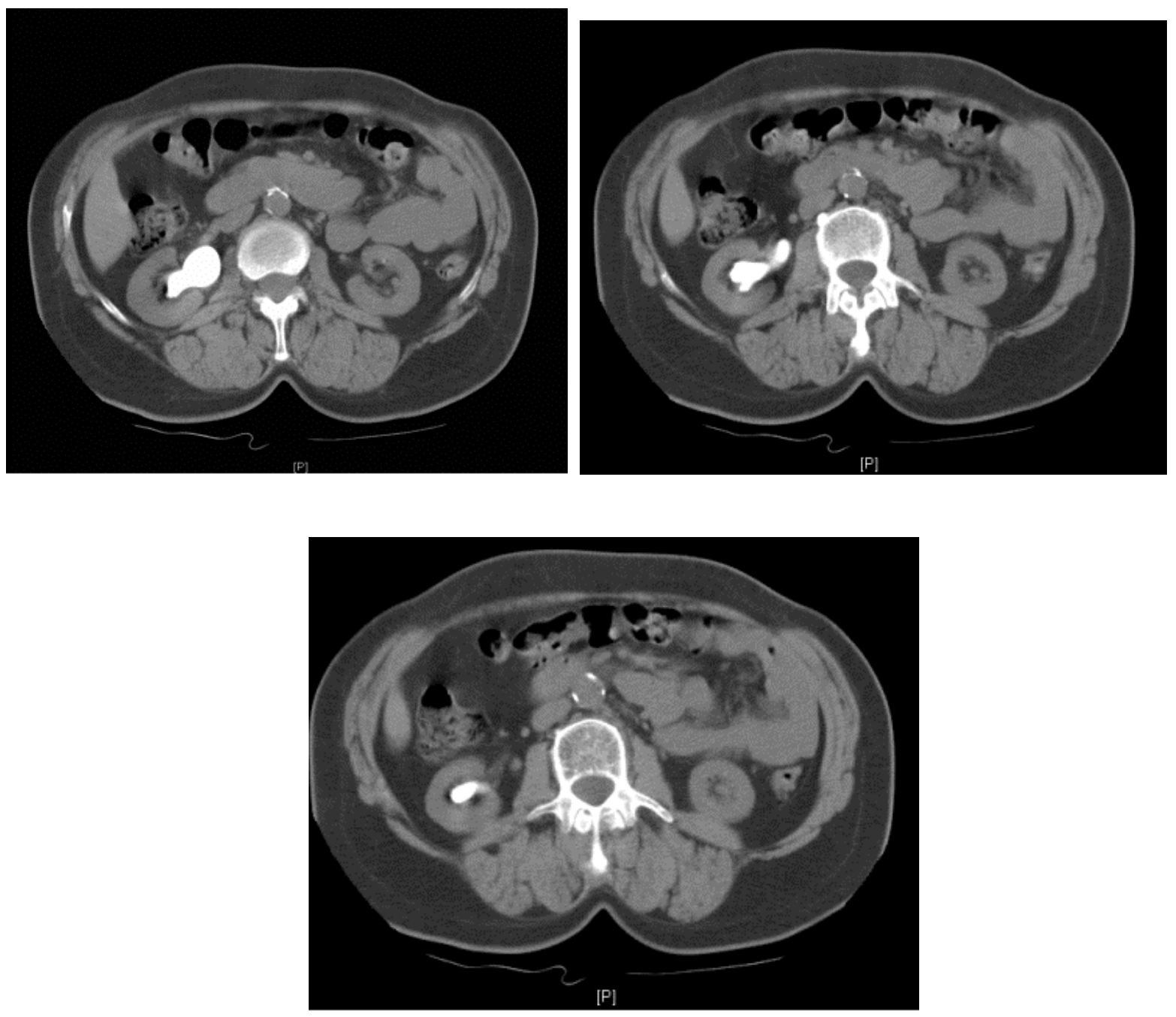

FIGURE 1. Computed Tomography with axial images through renal pelvis and ureteropelvic junction demonstrating large preoperative calculus burden. 


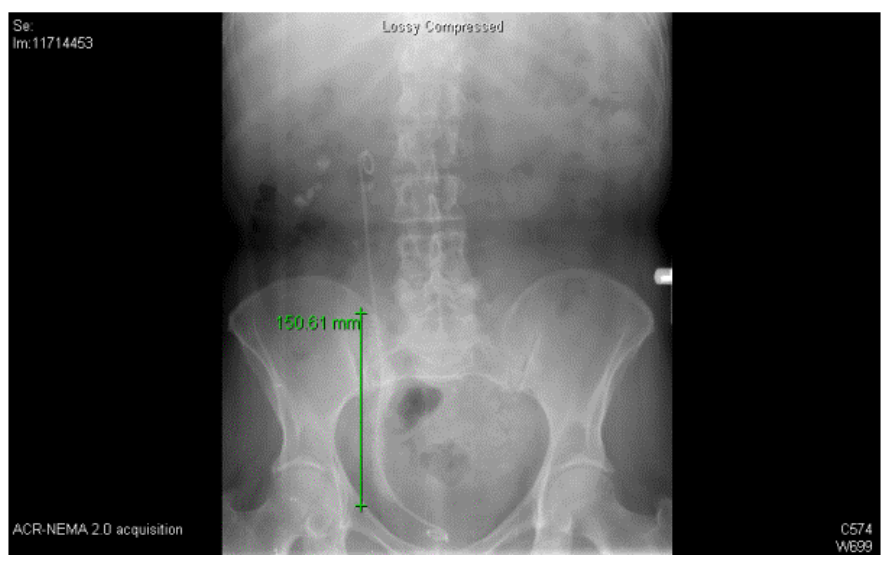

FIGURE 2. Plain radiograph demonstrating massive postoperative steinstrasse..

KEYWORDS: nephrolithiasis, steinstrasse, calculus

Received October 3, 2006; Revised February 27, 2007; Accepted March 5, 2007; Published xx, xx, 2007

A 63-year-old female presented with a symptomatic $2.2 \times 3.8 \mathrm{~cm}$ right renal stone. After discussion of options for management, she chose minimally invasive treatment. A stent was placed after treatment with right ureteroscopy and laser lithotripsy. She represented with steinstrasse along the length of the stent. This was treated with a combination of ureteroscopy and extracorporal shock wave lithotripsy (ESWL) using 2400 shocks at 24 kilovolts with complete resolution of the steinstrasse.

Steinstrasse may occur after ESWL and is often transient and asymptomatic. Up to one-third of patients may present with silent obstruction and resultant loss of renal function[1]. Steinstrasse usually involves only part of the ureter, and complete ureteral involvement, as in this case, is rare. Abdel-Khalek, et.al. reviewed 2954 patients with renal stones who underwent ESWL. Steinstrasse occurred in 146 cases (4.9\%), which resolved spontaneously in $73(50 \%)$ [2]. In a separate review, Weinerth, et.al. showed that large stone burdens $(1.7 \mathrm{~cm}$ or greater) and bilateral treatements were the largest predisposing factors for the development of steinstrasse[3].

Steinstrasse is a known complication of the treatment of large renal calculi. Since many cases can be associated with asymptomatic obstruction, postoperative imaging is essential for early identification to avoid significant morbidity.

\section{REFERENCES}

1. Madbouly, K. et al. (2002) Risk factors for the formation of a steinstrasse after extracorporeal shock wave lithotripsy: a statistical model. J Urol. 167 (3), 1239-1242.

2. Abdel-Khalek, M. et al. (2004) Prediction of success rate after extracorporal shock-wave lithotripsy of renal stonesa multivariate analysis model. Scand J Urol Nephrol. 38(2), 161-167.

3. $\quad$ Weinerth, J.L. et al. (1989) Lessons learned in patients with large steinstrasse. J Urol 142(6), 1425-1427.

This article should be cited as follows:

Pugliese, J. and Peterson, A. (2007) Massive steinstrasse after treatment of a staghorn calculus. TheScientificWorldJOURNAL 7, 504-505. DOI 10.1100/tsw.2007.96. 


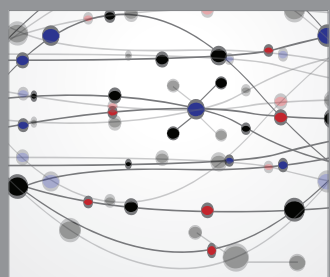

The Scientific World Journal
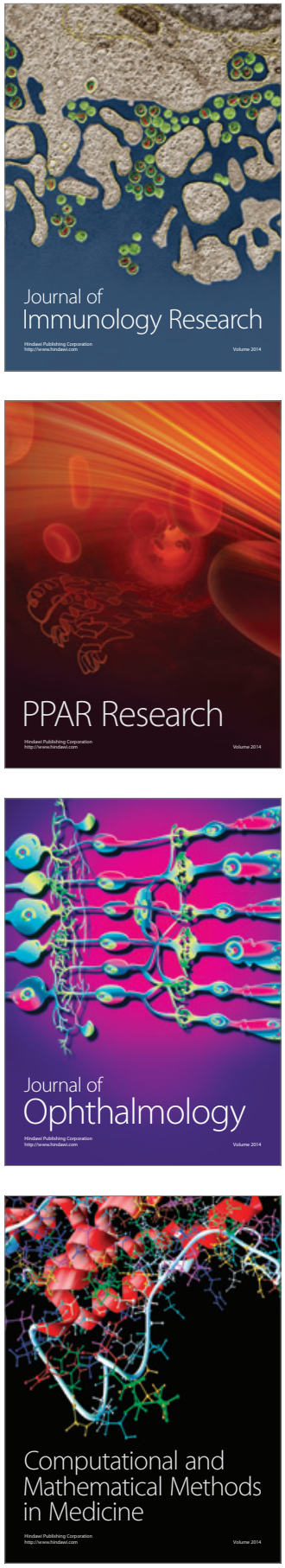

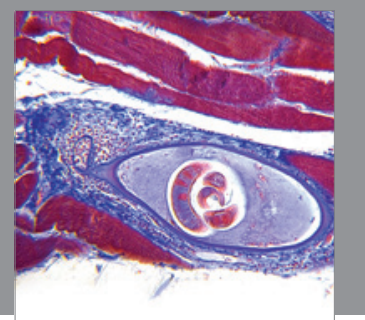

Gastroenterology

Research and Practice
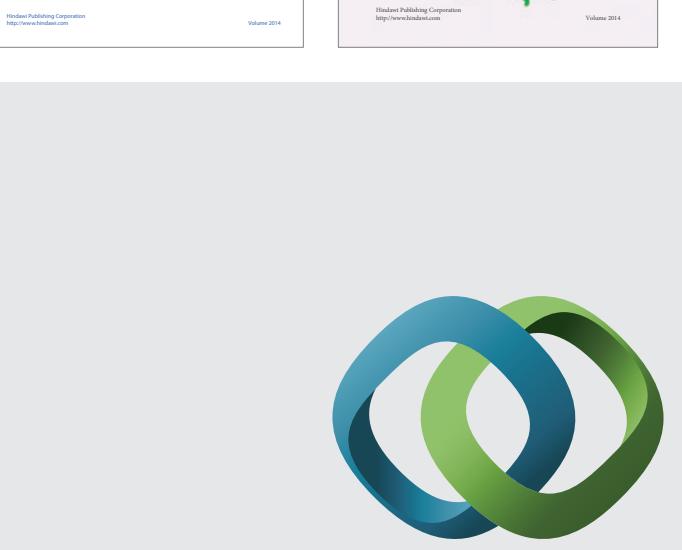

\section{Hindawi}

Submit your manuscripts at

http://www.hindawi.com
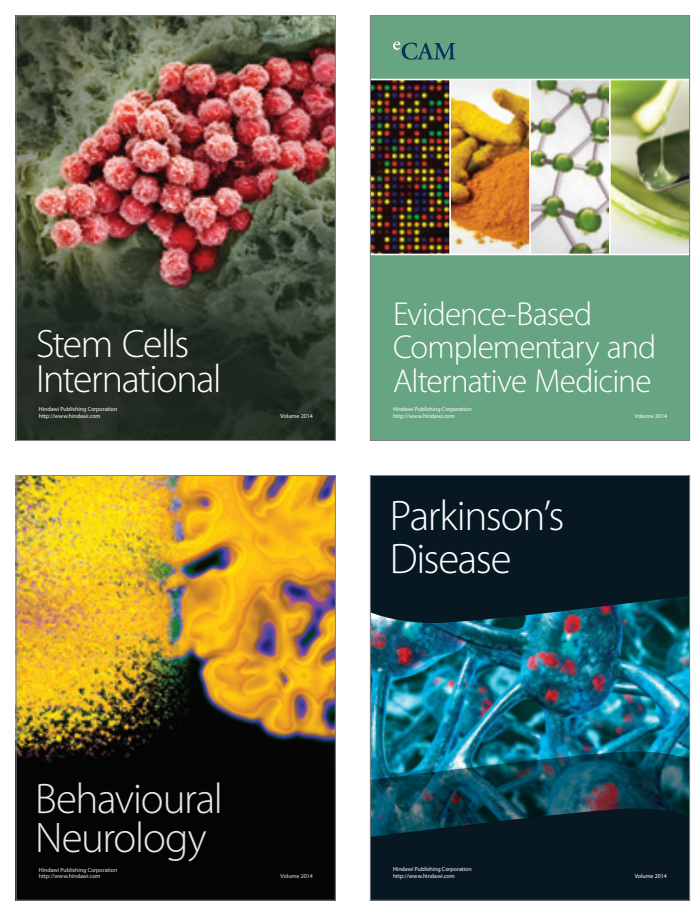

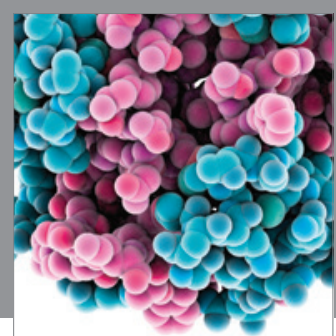

Journal of
Diabetes Research

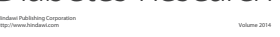

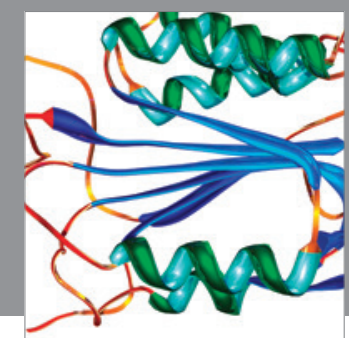

Disease Markers
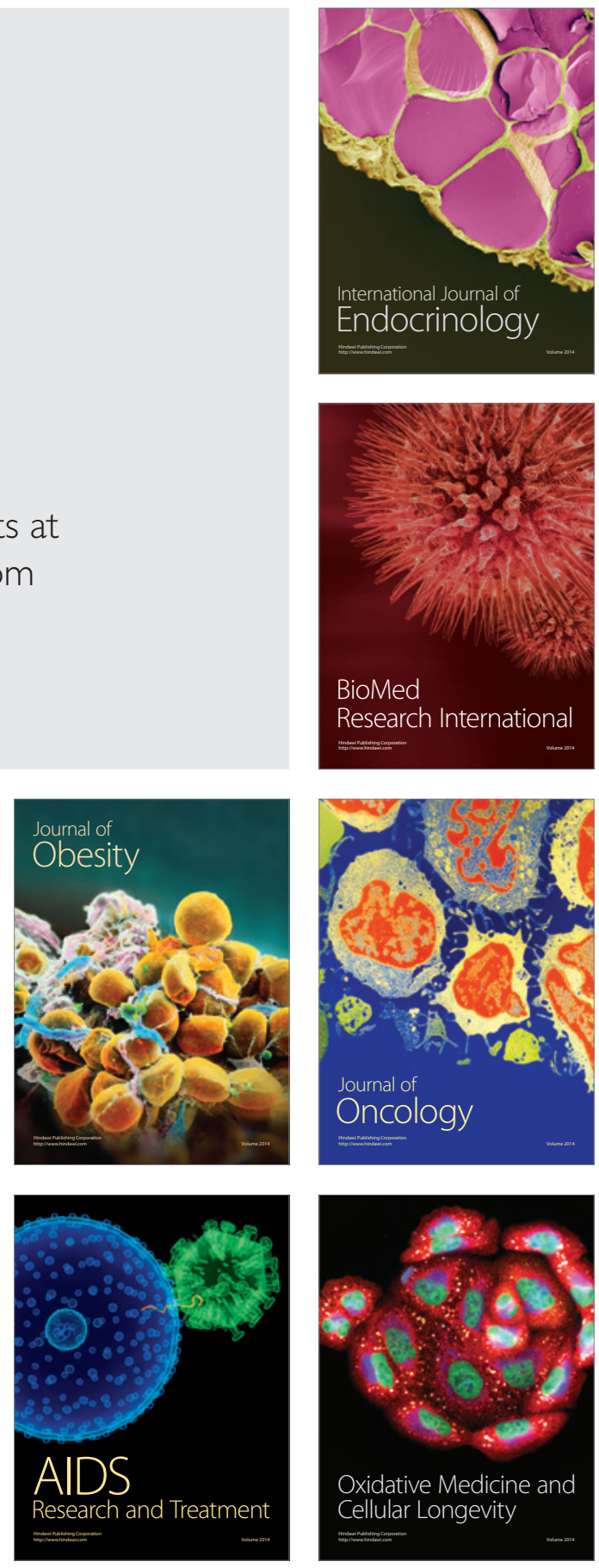